\title{
PRÁTICAS PEDAGÓGICAS DE ALFABETIZAÇÃO: UM LEVANTAMENTO EM PERIÓDICOS DA ÁREANO PERÍODO DE 2010 A 2014
}

\author{
VIVIAN ANNICCHNI FORNER \\ Mestranda em Educação no Programa de Pós-Graduação em Educação da Pontífica Universidade Católica de Campinas/SP. \\ Graduada em Pedagogia. E-mail: vivianforner@gmail.com \\ ELVIRA CRISTINA MARTINS TASSONI \\ Doutora em Educação. Professora do Programa de Pós-Graduação em Educação da Pontífica Universidade Católica de \\ Campinas/SP. E-mail: cristinatassoni@ puc-campinas.edu.br
}

\section{RESUMO}

Esse artigo apresenta uma pesquisa bibliográfica, norteada pelo seguinte problema: o que os artigos publicados nos periódicos qualificados na área da educação têm discutido sobre as práticas pedagógicas de alfabetização. $\mathrm{O}$ objetivo foi analisar o que esses artigos têm problematizado em relação a tais práticas. A pesquisa reitera as transformações sofridas pelo conceito de alfabetização, que alteram a compreensão desse conceito. Fundamenta-se teoricamente na concepção de linguagem como forma de interação, assumindo a interdependência entre alfabetização e letramento. A base de dados foi o Portal de Periódicos da CAPES e a expressão para busca foi "práticas pedagógicas de alfabetização". Foram selecionados 23 artigos para estudo aprofundado, possibilitando a construção de cinco categorias: Estratégias de monitoramento de capacidades linguísticas; Concepções de professores sobre alfabetização e letramento; Políticas educacionais e currículo; Formação de professores e práticas pedagógicas; Alfabetização e as dificuldades de aprendizagem. Os resultados destacaram problematizações significativas para pensar o ensino e a alfabetização, mas, revelaram grande descompasso entre as práticas pedagógicas e os estudos teóricos contemporâneos. Algumas tendências foram identificadas nessas discussões, que ainda encontram grandes desafios: a alfabetização desenvolvida no contexto das práticas de leitura e de escrita enfrenta as incompreensões conceituais relacionadas ao letramento e à própria alfabetização, resultando em práticas pautadas pela repetição e controle; as dificuldades no processo de alfabetização têm levado a se repensar o ensino, mas, ainda geram encaminhamentos frequentes a especialistas, pois são consideradas dificuldades dos alunos; a interface com outras áreas de conhecimento é evidente, mas o risco de prescrições é grande, configurando certa supremacia de uma área sobre a outra; uma concepção de formação de professores que considera as demandas específicas de cada escola, versus uma formação universal.

Palavras-chave: Alfabetização. Formação de professores. Pesquisa bibliográfica.

\section{PEDAGOGICAL PRACTICES OF INITIAL READING INSTRUCTION: A SURVEY IN PERIODICALS OF THE AREA IN THE PERIOD FROM 2010 TO 2014.}

\begin{abstract}
This article presents a Bibliographical Review, guided by the following problem: what is discussed on published periodical articles in the area of education on the pedagogical practices of initial reading instruction. The objective was to analyze what these articles have problematized regarding such practices. This research reiterates the transformations undergone during early reading instruction, which alter the understanding of this concept. This article is theoretically based on the conception of language as a form of interaction, assuming the interdependence between initial reading instruction and literacy. The database was the CAPES Portal of E-Journals and the search term was "pedagogical practices of initial reading instruction". We have selected 23 articles for in-depth study, enabling the
\end{abstract}


construction of five categories: Monitoring strategies of linguistic capabilities; Teacher's conceptions on literacy and initial reading instruction; Educational policies and curriculum; Teacher training and teaching practices; Initial reading instruction and learning difficulties. The results highlighted significant problems to reflect on when teaching and during early reading instruction, but revealed a great mismatch between pedagogical practices and contemporary theoretical studies. Some trends have been identified in these discussions, which still face great challenges: the initial reading instruction developed throughout the context of reading and writing practices faces the conceptual misunderstandings related to literacy and to the initial reading instruction itself, resulting in practices guided by repetition and control; The difficulties in the initial reading instruction process have led to an entire rethinking of teaching, but still generate frequent referrals to specialists, since they are considered difficulties of the students; The interface with other areas of knowledge is evident, but the risk of prescriptions is great, configuring certain supremacy of one area over the other; A conception of teacher training that considers the specific demands of each school, versus a universal formation.

Keywords: Initial reading instruction; Teacher's Academic Background; Bibliographical Review.

\section{Introdução}

A área da alfabetização tem sido pesquisada e problematizada com muita intensidade. Desde 1980 grandes estudos e pesquisas foram alterando as concepções sobre a alfabetização e, consequentemente, impulsionando uma revisão das práticas pedagógicas desenvolvidas até então. Esse cenário de mudanças conceituais e teóricas, bem como a necessidade de pensar outras formas de ensinar a ler e escrevertem promovido um intenso movimento em torno da formação de professores.

Acrescido a esse contexto, temos o difícil panorama que as avaliações em larga escala vêm denunciando. Todo esse conjunto de fatores tem gerado mecanismos de controle sobre a escola e os professores. Nesse sentido, Scheibe (2010, p. 985) comenta que

[...] observa-se, hoje, grande pressão para que os professores apresentem melhor desempenho, principalmente no sentido de os estudantes obterem melhores resultados nos exames nacionais e internacionais. As críticas ressaltam, sobretudo, os professores como mal formados e pouco imbuídos de sua responsabilidade pelo desempenho dos estudantes.

Os movimentos de responsabilização do professor pelas mazelas da educação não são desconhecidos. Por outro lado, as discussões sobre a formação em serviço de professores alfabetizadores, já apontou como um dos grandes desafios, a busca de maneiras de os estudos recentes contribuírem, efetivamente, para a promoção de mudanças nas práticas da sala de aula (KRAMER, 2008). 
Nesse sentido,o objetivo da pesquisa aqui apresentada foi analisar o que os artigos publicados nos periódicos qualificados na área da educação têm problematizado em relação às práticas pedagógicas de alfabetização. A base de dados foi o portal de periódicos da CAPES (Coordenadoria de Aperfeiçoamento Pessoal de Nível Superior), no período de 2010 a 2014, buscando identificar tendências em relação às discussões sobre as práticas pedagógicas de alfabetização.

\section{Os caminhos da alfabetização}

O conceito de alfabetização está em constante transformação, o que se reflete nas relações entre educação e sociedade. Para apresentar um rápido panorama da alfabetização, baseamo-nos em Perez (2008), que aponta vários momentos em que movimentos sociais, políticos e religiosos vão trazendo mudanças no cenário da sociedade e da alfabetização. A autora destaca a Antiguidade Clássica, o Período Medieval, a Reforma Protestante de Martin Lutero, a Revolução Francesa e a Contra Reforma.

$\mathrm{Na}$ Antiguidade Clássica, o foco da alfabetização era a leitura oral e ser alfabetizado era participar das leituras públicas, nas quais os que liam, transmitiam as histórias e seus conhecimentos por meio do diálogo. Havia forte ênfase na memória. No Período Medieval,a oralidade e a memorização continuam a ser enfatizadas - o mestre fala e instrui e, o aprendiz ouve e memoriza. Mas, nesse período, a escrita começa a ganhar um espaço maior e passa a ser um instrumento para o trabalho intelectual. Perez (2008)destaca que, durante a Reforma Protestante de Martin Lutero, ser alfabetizado era estar na escola, sendo a escola do povo, a escola elementar e, a alfabetização consistia em ler e realizar operações matemáticas básicas, ainda pautadas em ensinamentos cristãos. É na Revolução Francesa, período que se caracterizou como promessa de ascensão social para os camponeses com vistas à hegemonia econômica, que a alfabetização começa a ter a leitura e a escrita como processos mais articulados. Entretanto, com a Contra Reforma,a alfabetização, que eraministrada por clérigos, retoma o ensino inicial da leitura e depois da escrita. Nessa época mulheres, artesãos e pequenos comerciantes tinham pouco acesso à leitura. Os materiais didáticos eram as cartilhas e a alfabetização em nível rudimentar era oferecida aos níveis mais baixos da população.

No Brasil, a educação básica elementar era destinada às populações indígenas e aos filhos de colonos e a educação média para a elite. Foram os jesuítas que, por meio da educação elementar, envolvendo o falar, ler e escrever, os cálculos básicos, além de música e canto, buscaram submeter os índios à obediência, à fé católica, focados na cristianização. A ascensão do Marquês de Pombal e as 
Reformas Pombalinas levam à expulsão dos jesuítas das colônias, acabando com seus projetos de educação. Foram criadas as aulas régias, que eram cursos ministrados na colônia por professores formados pelos seminaristas dos jesuítas, ou seja, o projeto educacional não está mais nas mãos dos jesuítas e da Companhia de Jesus, mas o modelo pedagógico não foi alterado - pautado pela repetição e repressão.

Ainda segundo Perez (2008), a visão positivista marca o trabalho com a alfabetização, enfatizando a soletração e a silabação por meio do reforço para obter resultado, assim, ser alfabetizado era receber o conhecimento por meio de métodos de repetição que eram controlados pelo reforço. Com o movimento da Escola Nova, o foco passa a ser o aluno. Dessa forma, as necessidades individuais da criança foram observadas, ser alfabetizado era passar em testes de níveis, e conseguir se desenvolver em um ambiente facilitador. Buscava-se uma participação mais ativa dos alunos, e se defendia a leitura do mundo.

No Pós Guerra (Segunda Guerra Mundial), há um movimento pensando na paz, na democracia e no desenvolvimento econômico, dando maior ênfase na educação como necessária para a mudança do país. Com a Constituição de 1946 há a universalização da alfabetização e maior acesso à educação elementar. O desenvolvimento decorrente da industrialização cria necessidades que vão além do domínio da leitura e da escrita, exigindo um ensino para o domínio das competências impostas pelo mercado de trabalho.Portanto, por força do capitalismo, o objetivo era gerar mão de obra através da universalização da alfabetização e da escola de massa. Nesse sentido, ser alfabetizado era estar capacitado para o mercado de trabalho. A educação ainda possuía caráter dualista, sendo a elite educada para as universidades, para a intelectualidade (PEREZ, 2008).

A partir de 1960 surgem pensamentos pedagógicos que buscavam mudanças sociais e políticas na sociedade capitalista da época, há então, uma visão de alfabetização como ato político, ou seja, uma alfabetização autônoma, conceito elaborado por Paulo Freire.

Em 1970 a alfabetização volta-se para a formação do sujeito funcional, que precisa se encaixar nos moldes da sociedade. Nesse período, as autoras Emilia Ferreiro e Ana Teberosky (1985), com suas pesquisas,passaram a descrever a gênese e o desenvolvimento da escrita no pensamento infantil. Discutiramo que as crianças pensam sobre a escrita e como se relacionam com ela antes e durante o período de alfabetização, considerando que o adulto tem o papel de criar condições que estimulem os conflitos cognitivos das crianças e, nesse sentindo, a escrita é considerada como um objeto de conhecimento. 
Outro estudo importante para a alfabetização foi o realizado por Vygotsky e Luria (VYGOTSKY, et. al., 1991), na década de 1920. Ambosproblematizaram o que leva a criança a escrever, investigando a compreensão de crianças não alfabetizadas sobre uma das funções da escrita o registro mnemônico (escrever para se lembrar depois).

Ambas as pesquisas revelam que a criança não é indiferente perante as práticas de leitura e de escrita. Com as publicações dos trabalhos de Ferreiro e Teberosky, seguidos pelos de Luria e Vygotsky, observa-se um movimento que impulsiona a necessidade de reformulações nas teorizações sobre a alfabetização e as práticas pedagógicas decorrentes, entendendo que, a alfabetização é um processo de construção do sujeito cognoscente. Tal processo é mais flexível e diversificado, centrado na necessidade do aluno evinculado aos conhecimentos prévios do mesmo.

Em 1990, as discussões sobre a alfabetização começam a ser influenciadas pelo conceito de letramento, que busca ampliar o que se entende por alfabetização, focalizando-se nos usos sociais nos quais as habilidades de leitura e escrita são necessárias. Segundo Soares (1998, p. 18), letramento refere-se ao "estado ou condição que adquire um grupo social ou um indivíduo como consequência de ter-se apropriado da escrita" Defende-se, a ideia de alfabetizar letrando, um processo ativo em que a criança está inserida desde muito cedo e no qual constrói "hipóteses sobre a natureza e o funcionamento da língua escrita, compreendida como um sistema de representação” (BRASIL, 2008, p. 10).

No início do século XXI, o conceito de alfabetização incorpora uma multiplicidade de sentidos, um conceito plural: o da variação linguística, que defende a ideia de que os modos de falar e escrever vão variar de acordo com os contextos. Nesse sentido, uma das principais dimensões do processo de aquisição da linguagem é a habilidade do falante modificar seu comportamento linguístico em função da situação social em que se encontra: tipo de relação entre os interlocutores, o tema da conversação e o local.

Esse cenário de mudanças conceituais e teóricas, bem como a necessidade de pensar outras formas de ensinar a ler e escrevertêm promovido um intenso movimento em torno da formação de professores. Considerando que a temática da formação de professores deveria estar articulada com as discussões sobre as práticas pedagógicas, a pesquisa aqui apresentada possibilitou, a partir do levantamento bibliográfico realizado, identificar as aproximações entre as práticas pedagógicas de alfabetização e as produções teóricas mais recentes na área. 


\section{A pesquisa bibliográfica - conhecendo nosso território}

A investigação contou com o recurso da internet para a coleta das informações, que possibilitou a identificação dos artigos de interesse da pesquisa, no site da CAPES, no link Portal de Periódicos, utilizando a expressão "práticas pedagógicas de alfabetização".

A internet tem se constituído como uma rica fonte de pesquisa para uma diversidade de áreas de conhecimento, pois representa

[...] um extraordinário acervo de dados que está colocado à disposição de todos os interessados, e que pode ser acessado com extrema facilidade por todos eles, graças à sofisticação dos atuais recursos informacionais e comunicacionais acessíveis no mundo inteiro (SEVERINO, 2002, p. 133).

As informações foram submetidas às etapas de análise inspiradas em Bardin (2011): a préanálise; a exploração do material coletado; e o tratamento das informações obtidas, a inferência e a interpretação.

A pré-análise refere-se ao momento inicial de organização de procedimentos de busca por meio de descritores que possibilitam rastrear as produções a serem submetidas à análise. Nesse sentido, inicialmente, foi realizada uma familiarização com o site para se definir o tipo de busca e a forma de pesquisa. Usamos o descritor "práticas pedagógicas de alfabetização"na base eletrônica da CAPES e com o filtro no próprio site, que identifica as teses e os artigos, encontramos 132 trabalhos, sendo 60 teses e 72 artigos. Diante do problema de pesquisa, que envolve apenas os periódicos, trabalhamos inicialmente com o conjunto de 72 artigos.

A partir de uma leitura flutuante dos títulos houve o estabelecimento de critérios de exclusão dos artigos para que se identificasse aqueles trabalhos que fariam parte da pesquisa. Foram excluídos os artigos repetidos; os artigos que apresentaram ano inferior ao estipulado, ou seja,anterior a2010; os com Qualis inferior a B3; e os que não apresentaram relações com a alfabetização. Dessa forma, 25 artigos foram selecionados para compor a pesquisa.

Passamos para o momento que Bardin (2011) denominou de exploração do material, que consiste em estudo aprofundado do conjunto coletado, lançando mão de procedimentos de categorização. Esta é a fase de leitura completa das produções e o fichamento de cada uma. Nesse momento, o objetivo foi identificar como aquele texto estava abordando a prática docente no que se refere à educação, especificamente, no tocante à alfabetização. Foram analisados o problema, o tipo de 
pesquisa, os aspectos teóricos, a metodologia, os resultados e qualquer outro indício que gerasse indagações. Também foram registradoso nome do periódico científico no qual se encontrava o artigo, bem como o Qualis do mesmo.

No decorrer dessa fase outros dois artigos foram excluídos, pois um deles tinha o objetivo de discutir, nas práticas de sala de aula, a qualificação técnica dos alunos para trabalhar no campo favorecendo a agricultura da região. O outro apresentou a experiência de um projeto de extensão, que visava criar condições para que alunos de baixa renda permanecessem na Universidade. A pesquisa teve por objetivo problematizar, a partir dessa experiência, o papel da Universidade no processo de transformação social, em relação à redução das desigualdades. A possível razão do nosso descritor "práticas pedagógicas de alfabetização" ter capturado esses dois artigos foi o fato de ambos trazerem a palavra prática pedagógica.

Portanto, a pesquisa foi composta por 23 artigos pertencentes aos seguintes periódicos, conforme a Tabela 1, abaixo:

Tabela 1 - Relação dos periódicos selecionados e a quantidade de artigos encontrada em cada um deles.

\begin{tabular}{cc}
\hline Nome da Revista & Quantidade \\
\hline Revista da UFSM & 1 \\
\hline Revista Brasileira de Linguística Aplicada & 1 \\
\hline Revista Meta: Avaliação & 1 \\
\hline Revista Internacional De Investigación En Ciencias Sociales Interdisciplinar & 1 \\
\hline Revista Lectura y Vida & 1 \\
\hline Revista Psicologia em Estudo & 1 \\
\hline Revista Latinoamericana de Ciencias Sociales, Niñez y Juventud & 1 \\
\hline Revista Veredas (UFJF. Online) & 1 \\
\hline Revista Bakhtiniana: Estudos do Discurso & 1 \\
\hline Revista Educação e Pesquisa & 2 \\
\hline Revista Psicologia: Teoria e Pesquisa & 2 \\
\hline Revista Psicologia: Reflexão e Crítica & 2 \\
\hline Revista Alfa: Linguística & 3 \\
\hline Revista CEFAC - Speech, Language, Hearing Sciences and & 5 \\
Education Journal &
\end{tabular}

Fonte: Dados da pesquisa das autoras.

Observamos que os artigos encontram-se em variadas revistas, havendo recorrência, em ordem decrescente, de artigos nas revistas CEFAC - Speech, Language, Hearing Sciences and Education 
Journal, com cinco deles; Revista Alfa de Linguística, com três; Revista Psicologia: Reflexão e Crítica, Revista Psicologia: Teoria e Pesquisa e Revista Educação e Pesquisa, cada uma com dois artigos. A revista CEFAC tem como foco a divulgação de trabalhos vinculados à área da saúde, especificamente a fonoaudiologia e educação. Seu público alvoé composto por fonoaudiólogos, psicopedagogos, psicólogos, professores, cirurgiões-dentistas e médicos. A revista Alfa tem como foco a divulgação de trabalhos vinculados à área da linguística. A Psicologia: Reflexão e Crítica tem como foco a divulgação de trabalhos vinculados à área do Desenvolvimento, da Avaliação Psicológica, dos Processos Psicológicos Básicos e da Psicologia da Saúde. A Revista Psicologia: Teoria e Pesquisa publica relatórios de pesquisa, estudos teóricos, relatos de experiências profissionais, revisão crítica da literatura, todos relacionados à psicologia. A Revista Educação e Pesquisa, conforme seu próprio nome diz, tem como foco a divulgação de trabalhos vinculados à área da educação. Em todas as revistas, o objetivo da divulgação dos trabalhos é o de aumentar a produção de conhecimento na área que ocupa e apresentar avanços para a mesma.

Achamos interessante citar queas revistas possuem as seguintes classificações Qualis: oito periódicos selecionados estão classificados com Qualis A1; cinco estão classificados com Qualis A2; seis estão classificados com Qualis B1; dois estão classificados com Qualis B2; e, outros dois periódicos possuem a classificação B3. É importante observar que há uma grande parcela dos artigos publicados em revista com estrato A.

\section{O que nos revelam as pesquisas sobre as práticas pedagógicas de alfabetização}

Durante o processo de aprofundamento das leituras dos 23 artigos, o tratamento dado ao conteúdo de cada um deles resultou na elaboração de cinco categorias. Tal processo pautou-se por aspectos de similaridade entre os textos. A Tabela 2, abaixo, apresenta as categorias e o número de artigos contemplados em cada uma delas.

Tabela 2 - Quantidade de artigos por categoria.

\begin{tabular}{lc}
\hline \multicolumn{1}{c}{ Nome Categoria } & Total \\
\hline Estratégias de monitoramento de capacidades linguísticas & 3 \\
\hline Concepções de professores sobre alfabetização e letramento & 4 \\
\hline Políticas educacionais e currículo & 5 \\
\hline Formação de professores e práticas pedagógicas & 7 \\
\hline Alfabetização e as dificuldades de aprendizagem & 4 \\
\hline
\end{tabular}

Fonte: Dados da pesquisa das autoras. 
Observa-se, portanto, uma concentração de artigos na categoria formação de professores e práticas pedagógicas, fato relevante para a presente pesquisa, que tem ambos os aspectos como objeto de investigação.

Na sequência apresentamos cada categoria de maneira detalhada.

\section{Estratégia de monitoramento de capacidades linguísticas}

Essa categoria é composta por três artigos que problematizam a relação das práticas pedagógicas na perspectiva de atitudes que podem ser tomadas, tanto por professores quanto por alunos, para que o desenvolvimento das capacidades de escrita e leitura seja potencializado. Abordam a valorização da escrita e da leitura como imprescindíveis para a aprendizagem.

Coelho e Correab (2010) discorrem sobre a capacidade leitora que pode se desenvolver a partir de estratégias que envolvem a técnica e a repetição, visando desenvolver a capacidade de antecipação com o objetivo de promover maior fluência na leitura.

Gutiérrez-Rodríguez e Flórez-Romero (2011) pesquisaram sobre a capacidade da escrita, trazendo como discussão o fato de os alunos do ensino superior teremuma baixa competência na produção de textos escritos na modalidade acadêmica. Nesse sentido, os autores apontam que os professoresquando têm consciência desse fato, conseguemajudar seu aluno, com maior efetividade. Por outro lado, ao se manterem em uma postura de cobrança do texto em uma modalidade específica, não ajudam os alunos a compreenderem o processo de elaboração e nem a superar tais incompreensões. Os autores discutem a necessidade de se ter propostas de programas de alfabetização acadêmica.

Massignan et. al. (2012) apresentam a dramatização de histórias infantis como estratégiapara desenvolver a compreensão leitora dos alunos.Afirmam que há um aprimoramento de tal compreensão, quando as crianças participam de dramatizações que envolvam narrativas.

Os três artigos valorizam a escrita e a leitura como imprescindíveis para a integração social, para a apreensão de novos conhecimentos e como ferramenta para o pensamento e para o desenvolvimento de estratégias de aprendizagem.

\section{Concepções de professores sobre alfabetização e letramento}

Essa categoria foi contemplada com quatro artigos que problematizam como as práticas dos professores abordam as relações e as diferenças entre ambos os conceitos. Discorrem sobre o fracasso 
escolar decorrente de práticas de ensino que privilegiam o controle do desempenho escolar a partir da determinação de padrões de êxito que favorecem a homogeneidade e não o raciocínio, reduzindo a linguagem escrita a codificação e decodificação de signos, excluindo as suas possibilidades de significado e necessidade para integração social.

Berberian et. al (2013) discorrem sobre o fato de a maioria dos professores participantes da pesquisa realizada não compreender a diferenciação entre os conceitos de letramento e alfabetização, como também não estabelecer relação entre ambos. Fator que, segundo os autores, faz com que esses professores desenvolvam um ensino voltado apenas para o código e a técnica. Apesar dos dados alarmantes da pesquisa de Berberian et. al (2013), os autores compreendem que a apropriação da linguagem escrita é uma condição necessária para que se o cidadão possa usufruir de seus direitos e, dessa forma, participar da sociedade. Concluem que a fonoaudiologia inserida na escola, em uma perspectiva colaborativa com professores, pode auxiliar a qualidade do ensino.

Guzmán e Guevara (2010) pesquisaram as concepções de infância e sobre a compreensão de estratégias que podem contribuir para o processo de alfabetização, comparando as respostas de professores de Educação Infantil com formação em Pedagogia, com as respostas de outros profissionais da Educação Infantil, sem a respectiva formação. Identificaram que os pedagogos consideram a criança um sujeito de direitos, enquanto os outros profissionais entendem que a criança apenas precisa de cuidados. Em relação ao processo de alfabetização, mostraram que os professores com formação em Pedagogia destacaram como estratégia importante o letramento, conceituado como um processo que se inicia quando as crianças entram em relação com outros sujeitos, por meio de práticas sociais de leitura e de escrita e, que se aprimora por toda a vida. É possível destacarmos nessa pesquisa que a formação inicial, mesmo com todos os problemas que a assolam, acaba trazendo mudanças na concepção do professor.

Por outro lado, o artigo de Monteiro (2010) confirma ainda a existência de práticas pedagógicas de uma professora alfabetizadora que são voltadas para a submissão e a docilidade dos alunos, investindo em comportamentos de respostas únicas, visando o controle da disciplina e do desempenho. Monteiro (2010) estabelece uma relação entre o sucesso e o fracasso escolar com as práticas que controlam e disciplinam. A submissão e a dependência demonstrada pelos alunos impedem que os mesmos arrisquem, questionem e avancem em sua aprendizagem.

Szymanski e Brotto (2013) apresentam dados de um curso de extensão que identifica como maior dificuldade dos professores o entendimento sobre o letramento e a alfabetização. Nesse sentido, 
os autores responsabilizam a formação inicial, pois, o que se observa são novos discursos e velhas práticas.

Todos os quatro artigos, portanto, discorrem sobre o fracasso escolar decorrente de práticas de ensino que privilegiam o controle do desempenho escolar a partir da determinação de padrões de êxito que favorecem a homogeneidade e não o raciocínio, o que torna a linguagem escrita um processo de codificação e decodificação de signos, excluindo as suas possibilidades de significado e deinserção social. Outro aspecto evidenciado nas pesquisas é a contradição existente entre a constatação das influências da formação inicial para as concepções dos professores e a constatação de que apesar da formação veicular um discurso novo, as práticas são velhas. Da mesma forma, as concepções equivocadas dos professores investigados em relação à alfabetização e o letramento, revelam que os estudos mais recentes nessa área pouco interferem nas práticas pedagógicas. É comum encontrarmos professores que acreditam que é muito importante ler todo o dia para os seus alunos, mas as atividades propostas giram entorno de cópia, memorização e repetição.

\section{Políticas educacionais e currículo}

Os cinco artigos que compõem essa categoria problematizam a importância da qualidade da educação,que pode ser alcançada por meio da avaliação da aprendizagem e da formação rigorosa do professor, para que, dessa forma, a escola cumpra sua função social transformadora, ou seja, permitir que o professor, além da construção de conhecimentos com seus alunos, favoreça momentos de imaginação e criação aos mesmos. Dentre esses artigos, dois fazem uma reflexão dos desafios enfrentados durante a ampliação do Ensino Fundamental para nove anos. Kramer,et. al. (2011) e Rocha (2010) discutem sobre as mudanças envolvidas nessa ampliação, que trazem muita estranheza às famílias e à própria escola, que muitas vezes não sabe como informar sobre tais mudanças. Outro aspecto problematizado refere-se aos conteúdos que, segundo os autores, têm se mantido os mesmos; ou seja, continua se reproduzindo o que se ensina anteriormente à ampliação do ensino fundamental.

Cristofolini (2012) discute a importância da Provinha Brasilpor ser um instrumento de avaliação em larga escala, que traz um panorama em relação ao domínio de habilidades necessárias para a leitura e a escrita. Defende que a alfabetização deve se dar de forma sistemática, explorando habilidades como a consciência fonológica. 
Barbosa da Silva e Silva Neto (2013) observam como os conteúdos propostos pelo currículo do ensino médio, são abordados por uma professora que, segundo as autoras, possui uma prática padronizada e coerciva. Nesse sentido, demonstram que, perante os recursos didáticos utilizados pelo professor, o que se vê são atividades que desenvolvem questões programadas com ênfase na gramática normativa da língua, de uma forma bastante descontextualizada para os alunos. Mais uma vez, observamos pesquisas que denunciam a alfabetização calcada no treino e na técnica pela técnica.

Leite e Elliot (2010) apontam que os professores são alfabetizadores por falta de escolha e defendem a implantação de um programa que os capacite e os motive para tal ato. Assim, apresentam tal proposta como um desafio tanto para as políticas públicas, como também para a formação continuada de professores, a fim de se buscar caminhos para aumentar o interesse e envolvimento dos professoresno trabalho com a alfabetização.

Em síntese, todos os cinco artigos discutem a importância da qualidade da educação, que pode ser alcançada por meio da avaliação da aprendizagem e da formação cuidadosa e criteriosa do professor, para que, dessa forma, a escola cumpra sua função social de produzir conhecimentos e promover a aprendizagem efetiva dos alunos.

\section{Formação de professores e práticas pedagógicas}

Essa categoria foi contemplada com sete artigos que problematizam, além da formação,a postura dos professores alfabetizadores em sala de aula e a fonoaudiologia, utilizando-se de propostas que envolvem o letramento.

O artigo de Zibetti e Souza (2010) analisa a prática pedagógica de uma professora alfabetizadora e, por meio de sessões de observação, evidencia a importância da formação teórica, mas destaca que é, igualmente importante, que o professor lance mão de estratégias criadoras que enriqueçam o que havia sido planejado. Dessa forma, os autores afirmam que, além de considerar as bases teóricas fundamentais ao trabalho do professor, são necessárias práticas inovadoras durante a aula. Esse se mostra um caminho para atender as necessidades do contexto em que se encontra, considerando as características de cada aluno, as condições físicas do espaço que possui e o conteúdo que ensinará.

Oliveira e Natal (2012) abordam os frequentes encaminhamentos de crianças a outros profissionais, em razão de diferenças no percurso de desenvolvimento e de aprendizagem entre elas. Os 
autores expõem um difícil panorama educacional que evidencia o baixo desempenho dos alunos, que é atribuído à responsabilidade dos próprios educandos e de suas famílias. Ao pesquisarem o que os professores pensam sobre o desenvolvimento da linguagem escrita, observaram que a maioria considerou que o início do processo de desenvolvimento da linguagem escrita se dá na fase escolar, mas que os fatores que favorecem o processo dessedesenvolvimento estão relacionadosao contexto familiar. Assim, os próprios professores pesquisados confirmaram que as dificuldades no processo de aprendizagem são intrínsecas às crianças e às suas famílias, criando uma diversidade de patologias, levando a encaminhamentos para outros profissionais. Nesse sentido, defendem a necessidade do fonoaudiólogo auxiliar o professor para o melhor desenvolvimento da criança.

Mantendo a articulação entre educação e fonoaudiologia, Ribeiro e Souza (2012) relacionam aspectos voltados ao letramento e a alfabetização para o desenvolvimento do trabalho do fonoaudiólogo. Portanto, defendem que os conceitos de letramento e de alfabetização contribuem para complementar os trabalhos na área da fonoaudiologia, pois, consideram a noção de letramento útil para que se fundamentem os estudos da linguagem escrita através da circulação nas práticas letradas e na valorização do sujeito que a escreve.

O artigo de Eitelven e Fonza (2012) apresenta um curso de extensão que prioriza a realidade do professor e o que acontece em sua prática. Os autores discutem que é imprescindível que se estabeleçam meios para que o professor dialogue com a teoria e com a prática, para que possa questionar seus problemas e refletir sobre como resolvê-los. A partirdessa compreensão, os autores propõem um curso que envolve a análise dos conhecimentos de professores alfabetizadores e desenvolvem atividades para que as dificuldades apontadas por eles sejam superadas. Destacaram que as maiores dúvidas dos professores concentravam-se em torno da produção de texto, leitura, alfabetização e letramento. A partir disso, o curso buscou que os cursistas compreendessem a importância de "trabalhar a alfabetização para a criança ter o domínio do código escrito associado ao processo de letramento, visto que esse último dará sentido e motivação ao aluno, não privilegiando um sobre o outro, mas, sim, articulando-os" (EITELVEN; FONZA, 2012, p.15). Os autores defendem que as interações estabelecidas entre os professores constroem uma cultura que possibilita o desenvolvimentoda humanização, que é exercida de forma organizada e planejada pela escola. Isso reflete a importância da mediação do professor ao trabalhar com seus alunos.

O artigo de Saveli (2010)apresenta um diálogo entre universidade e comunidade, discorrendo sobre alunos do curso de Pedagogia que desenvolvem um programa de formação em serviço para 
jovens e adultos alfabetizadores, na cidade de Ponta Grossa, município que não possui condições para exigir formação específica a esses profissionais. Na proposta de formação, os temas de estudo eram definidos a partir das necessidades dos alfabetizadores, confirmando a tendência já apontada por Eitelven e Fonza (2012).

Os artigos de Cerutti-Rizzatti (2012) e Cyranka e Magalhães (2012) abordam a importância do trabalho com os gêneros discursivos e o fato de muitas vezes os professores não saberem explorar os mesmos. Dessa forma, Cerutti-Rizatti (2012) estabelece que é preciso ensinar a língua materna por meio do letramento considerando a linguística aplicada. Na mesma direção, Cyranka e Magalhães (2012), ao pesquisarem a oralidade e as variedades linguísticas no ensino da língua portuguesa, identificaram que os professores apresentam dificuldades em trabalhar uma concepção atual de língua como interação, a partir da pluralidade de discursos e textos, tanto orais, quanto escritos. A escola teria, para as autoras, dificuldade sobre a escolha de conteúdo, sendo que, pouco valoriza a oralidade como objeto de ensino.

Em síntese, cada um dos artigos discutiu possibilidades e expectativas de formação de professores alfabetizadores, que explorem as relações teoria e prática, visando que as práticas pedagógicas retratem as mudanças conceituais na área da alfabetização, incorporando de maneira reflexiva os conceitos de letramento, variação linguística, gêneros discursivos, entre outros. Da mesma forma, as relações entre teoria e prática devem partir das necessidades concretas da sala de aula.

\section{Alfabetização e as dificuldades de aprendizagem}

A última categoriaé composta por quatro artigos que problematizam as dificuldades que surgem durante o processo de alfabetização, bem como os distúrbios que comprometem a aprendizagem. Todos destacama necessidade de trabalhos que se constituam em caminhos para o enfretamento das dificuldades.

Crestani et. al. (2013)discutem a importância da identificação do Distúrbio Específico de Linguagem (DEL), focalizando apenas a necessidade de trabalhos que superem essas patologias das crianças. Realizaram uma pesquisa bibliográfica, mapeando a literatura nacional que aborda tal questão. Concluem que é preciso instrumentalizar os profissionais da saúde para que façam o diagnóstico e a prevenção do DEL, pois é possível promover mudanças no desenvolvimento da linguagem dos sujeitos, com orientações específicas e diagnósticos precisos. Por isso, as avaliações 
rotineiras das habilidades de linguagem e comunicação devem serconstantemente realizadas e analisadas.

Justino e Barrera (2012) alertam para os riscos de, ao enfatizar as práticas de leitura e de escrita, esquecer que para ensinar a ler e escrever é preciso mais do que participar de taispráticas. Discutem, a partir de vários autores, a forma como as abordagens construtivistas invadiram as escolas, levando a uma perda da especificidade do processo de alfabetização. Tal alerta explicita a defesa do ensino do código escrito propriamente dito, colocando luz nas habilidades metalinguísticas, que se referem a diferentes capacidades que permitem a reflexão e o controle consciente sobre o funcionamento do sistema alfabético de escrita. Segundo os autores

é importante realizar também uma reflexão sobre as políticas públicas atuais para a alfabetização que, ao privilegiarem as práticas pedagógicas voltadas para o letramento [...], muitas vezes acabam por negligenciar a importância do trabalho com a reflexão e a sistematização do código alfabético [...] Um ambiente favorável, uma metodologia adequada e um profissional interessado e capacitado para implementá-la contribuiria, sem dúvida, para a aprendizagem e o crescimento pessoal desses alunos (JUSTINO; BARRERA, 2012, p. 406)

Nesse sentido, Justino e Barrera (2012, p. 400) demonstram, por meio de investigação de campo, que alunos com importante defasagem na alfabetização, submetidos a treinos para o desenvolvimento, especificamente da consciência fonológica, uma das habilidades metalingüísticas essenciais para a alfabetização, "apresentam ganhos significativos em leitura e escrita quando comparados a grupos de alunos com características semelhantes e que não participaram da intervenção"

Nobre e Roazzi (2011, p. 326) apresentam uma pesquisa que confirma a relação entre a presença do realismo nominal em crianças e adultos e o baixo desempenho em leitura, escrita e matemática. Segundo os autores, o realismo nominal é uma característica do pensamento infantil, que impede a dissociação entre a palavra e o que ela significa, concebendo a mesma "como parteintegrante do objeto, atribuindo ao signo característicasdo objeto ao qual se refere". Participaram da investigação 54 sujeitos entre adultos e crianças. Os testes a que foram submetidos os levavam a: explicar o significado de palavras ditadas; responder sobre o tamanho das palavras; identificar palavras conhecidas e palavras inventadas, tanto oralmente, como por meio da escrita; resolver situações problemas, a fim de avaliar o raciocínio lógico e aritmético; categorizar sons; subtrair fonemas, identificar e produzir rimas. Concluíram, que "o realismo nominal influenciana compreensão da natureza arbitrária do sistema notacional alfabético e numérico” (NOBRE; ROAZZI, 2011, p. 333). 
Amaral et. al. (2011, p. 853) discorrem sobre as dificuldades de aprendizagem relacionadas a omissões ortográficas relacionadas a aspectos fonético-fonológicos da sílaba como um todo, ou em parte dela. Trata-se de uma investigação na área da fonoaudiologia, envolvendo textos escritos produzidos por crianças do último ano da educação infantil, no formato de listas de palavras. Os autores afirmam que é preciso considerar que "as crianças não se orientam apenas por características presentes na fala quando escrevem, mas trazem, também, para sua escrita, conhecimentos decorrentes de sua inserção histórica em práticas de letramento”. Os autores nomeiam de práticas de letramento, todas as situações de uso da escrita em sala de aula, como por exemplo, cartaz contendo as famílias silábicas. Portanto, para nós, os autores se referem às práticas escolares de circulação de informações sobre o sistema alfabético de escrita. As conclusões apontam para o caráter complexo das omissões ortográficas relacionadas às sílabas. A pesquisa parece ter uma estreita relação com os estudos de Ferreiro e Teberosky (1985), mesmo os autores não explicitando tal questão. Mas, ao destacarem como um dos resultados o fato de as crianças investigadas analisarem "a sílaba como unidade da língua (e da escrita) do que [como] suas partes" (AMARAL, et. al., 2011, p.853), demonstram tal aproximação. Reforçada ainda mais pelo destaque em relação à forma de avaliar as produções dessas crianças. Afirmam os autores "que não se deveria avaliar com o mesmo peso as omissões de sílabas como um todo e as omissões de partes de sílabas, nem mesmo as omissões de diferentes partes da sílaba (AMARAL, et. al., 2011, p.853). Inferimos que tais afirmações levam a considerar a aquisição da escrita um processo construtivo, pautado pela reflexão das relações som-letra.

Os artigos presentes nessa categoria apontam, em sua maioria, para uma necessidade de se recuperar o que é específico da alfabetização. No nosso ponto de vista, ao defenderem que as dificuldades de aprendizagem dos alunos na leitura e na escrita podem ser superadas por meio do desenvolvimento de habilidades metalingüísticas, sinalizam para a urgência da reinvenção da alfabetização, conforme nos propõe Soares (2004). Para a autora, devemos romper com o radicalismo! Não se trata de defender um ensino autônomo dos aspectos fonológicos, alfabéticos e ortográficos da escrita, dissociado das práticas de leitura e de escrita. Da mesma forma, não se trata de considerar "que a criança é capaz dedescobrir por si mesma as relações fonema-grafema,em sua interação com material escrito e por meio deexperiências com práticas de leitura e de escrita" (SOARES, 2004, p. 14). Portanto, dissociar alfabetização e letramento é um grande equívoco, pois 
Não são processos independentes, mas interdependentes,e indissociáveis: a alfabetização desenvolve-seno contexto de e por meio de práticas sociais deleitura e de escrita, isto é, através de atividades deletramento, e este, por sua vez, só se pode desenvolverno contexto da e por meio da aprendizagem dasrelações fonema-grafema, isto é, em dependência da alfabetização (SOARES, 2004, p. 14, grifos da autora).

A partir dos artigos apresentados em cada categoria, foi possível constatar que várias pesquisas defendem o pressuposto de que é importante olhar para o grupo dos alunos que se tem e buscar caminhos para um trabalho contextualizado. De fato, a alfabetização é um fenômeno multifacetado, pois tem interface com outras áreas de conhecimento, além da pedagogia. As pesquisas apontam a fonoaudiologia e a linguística, como as áreas que mais podem contribuir com o trabalho do professor alfabetizador. Sem dúvida os conhecimentos específicos e técnicos são fundamentais e devem ser considerados, mas a forma como a aproximação com a educação acontece precisa de um olhar mais crítico, pois, do contrário, pode cair na prescrição, se esquecendo do ensino de maneira contextualizada.

\section{Considerações Finais}

Este estudo possibilitou constatar algumas aproximações e alguns distanciamentos das práticas pedagógicas de alfabetização em relação aos estudos mais contemporâneos sobre a área em questão.Há muitos estudos que trazem aspectos importantes para se pensar o ensino e a alfabetização, no entanto, há um descompasso entre tais estudos e as práticas pedagógicas.

Quando as pesquisas problematizam a alfabetização como um processo de aprendizagem social, assumem como necessário ao cidadão a apropriação da linguagem escrita para que possa usufruir de seus direitos e participar da vida em sociedade. No entanto, observou-se que, quando o foco é a alfabetização e o letramento, as pesquisas defendem a articulação entre ambos, mas os dados apontam que há dificuldades, por parte dos professores, na compreensão de ambos os conceitos.

Sobre o ensino da leitura e da escrita de forma contextualizada, hápráticas pedagógicas sustentadas na ideia de tal contextualização, mas, há também, práticas pedagógicas pautadas pela repetição e controle. Da mesma forma, as estratégias de ensino, quando abordadas nas pesquisas, mostram-se, ora como defensoras de recursos que mantêm aspectos do letramento articulado à alfabetização e da importância da contextualização durante a aprendizagem da leitura e da escrita, e ora defendem estratégias que mantêm a mecanização. 
Nesse sentido, as dificuldades no processo de aprendizagem são por vezes citadas como únicas e exclusivas dos alunos e, um procedimento frequente é o encaminhamento aosespecialistas. Apesar disso, há pesquisas que defendem que essas dificuldades podem se relacionar não só ao aluno, como também ao processo de ensino e à escola.

Assim, quando se discute a interface da educação com outras áreas, encontramos pesquisas que defendem que quanto maior aproximação com outras áreas, mais possibilidades de compreender o fenômeno educativo, em especial a alfabetização. Entretanto, há outras que ao assumirem a relevância de tal aproximação, apresentam contribuições altamente prescritivas.Sobre esse assunto, deve-se dar atenção ao fato de parte significativa dos artigos selecionados na presente investigação evidenciar a fonoaudiologia como uma área de conhecimento importante para a formação dos professores. Isso pode se constituir em um grande risco de medicalizar ainda mais a educação. A forma como a aproximação com a educação acontece, especialmente com a alfabetização, necessita de um olhar mais crítico.

As políticas educacionais e a formação de professoressão aspectos que precisam ter destaque, poisobservamos uma maior concentração de artigos que abordam essas temáticas. O que identificamos foi que, apesar de existirem experiências de formação de professores, que partem das necessidades concretas da sala de aula, há políticas de formação que não consideram a realidade específica dos diferentes contextos e se distanciam da prática pedagógica diária dos professores.Dessa forma, se identifica a necessidade de compreender quem são esses professores alfabetizadores. Serão eles, professores recém formados, ou professores que não tiveram outra opção? Assim, as pesquisas vêm apontando que trabalhar com alfabetização não é uma escolha ou prioridade, é o que restou. Há um desinteresse pelo trabalho com as classes de alfabetização. O que causa isso? Seria uma questão estrutural? Será que a jornada de trabalho intensaacaba cansando e desmotivando o professor? Ou a formação que se distancia das necessidades que os professores têm, traz um sentimento de abandono?

A partir dessas inquietações e desses dados, há que se considerar as diferentes caracterizações desses trabalhos, onde uns abordam aspectos importantes do ensino, mas ainda com resquícios de uma radicalização cindindo alfabetização e letramento; e outros apontam aspectos que podem, realmente, favorecer positivamente no desenvolvimento da criança, evidenciando que a alfabetização é um processo intencional e sistemático, que necessita ser planejado e mediado.

Por fim, entende-se que, apesar de novas linhas teóricas comporem a lista de práticas pedagógicas de alfabetização, o que se verifica, na realidade diária, são professores perdidosem teorias 
e repetidores de discursos contemporâneos, mas com práticas marcadas por didatizações arcaicas. Há um desafio cada vez maior de aproximar os estudos teóricos das práticas pedagógicas.

\section{Referências}

AMARAL, A. S.; FREITAN, M. C. C.; CHACON, L.; RODRIGUES, L. L.Omissão de grafemas e características da silaba na escrita infantil. Revista CEFAC, 2011. Disponível em:

http://www.scielo.br/pdf/rcefac/v13n5/84-10.pdf.

BARBOSA DA SILVA, C. M. M.; SILVA NETO, J. G.A língua Portuguesa no ensino médio: conteúdos de ensino e o desenvolvimento da aula. Alfa: Revista de Linguística, 2013. Disponível em: http://www.scielo.br/pdf/alfa/v57n1/13.pdf.

BARDIN, L. Análise de conteúdo. Lisboa: Edições 70, 2011.

BERBERIAN, A. P.; BORTOLOZZI, K. B.; MASSI, G.; BISCOUTO, A. R.; ENJIU, A. J.;

OLIVEIRA, K. F. P. Análise do conhecimento de professores atuantes no ensino fundamental acerca da linguagem escrita na perspectiva do letramento. Revista CEFAC, 2013. Disponível em: http://www.scielo.br/pdf/rcefac/v15n6/219-11.pdf

BRASIL. Pró-Letramento - Programa de Formação Continuada de Professores dos Anos/Séries Iniciais do Ensino Fundamental: alfabetização e linguagem. Secretaria de Educação Básica - Brasília: Ministério da Educação, Secretaria de Educação Básica, 2008.

CERUTTI-RIZZATTI, M. E. Ensino de língua portuguesa e inquietações teórico-metodológicas: os gêneros discursivos na aula de português e a aula (de português) como gênero discursivo. Alfa: Revista de Linguística, 2012. Disponível em: http://nela.cce.ufsc.br/files/2014/10/Cerutti-Rizatti2012.pdf

COELHO, C. L. G.; CORREAB, J. Desenvolvimento da Compreensão Leitora através do Monitoramento da Leitura. Psicologia: Reflexão e Crítica (UFRGS), 2010. Disponível em: http://www.scielo.br/pdf/prc/v23n3/18.pdf

CRESTANI, A. H.; OLIVEIRA, L. D.; VENDRUSCOLO, J. F.; RAMOS-SOUZA, A. P.. Distúrbio especifico de linguagem: a relevância do diagnostico inicial. Revista CEFAC, 2013. Disponível em: http://www.scielo.br/pdf/rcefac/2012nahead/188-11.pdf 
CRISTOFOLINI, C. Refletindo sobre a provinha Brasil a Partir das dimensões sociocultural, Linguística e cognitiva da leitura.Alfa: Revista de Linguística (UNESP), 2012. Disponível em: http://seer.fclar.unesp.br/alfa/article/view/4967/4137

CYRANKA, L. F. M.; MAGALHÃES, T. G. O trabalho com a oralidade/variedades linguísticas no ensino de Língua Portuguesa. Veredas (UFJF. Online), v. 16, no 1, 2012. Disponível em: http://www.ufjf.br/revistaveredas/files/2012/10/Art-8-O-trabalho-com-a-oralidade-variedadesT\%C3\%A2nia-e-L\%C3\%BAcia-corrigidoformatado.pdf

EITELVEN, A. A.; FONZA, C. A. Batizando e ressignificando práticas pedagógicas no ensino da língua materna: o papel da formação continuada. Revista Brasileira de Linguística Aplicada, 2012. Disponível em: http://www.scielo.br/pdf/rbla/v12n1/a02v12n1

FERREIRO, E.; TEBEROSKY, A. Psicogênese da língua escrita.Porto Alegre: Artes Médicas, 1985.

GUTIÉRREZ-RODRÍGUEZ, M. J.; FLÓREZ-ROMERO, R. Enseñar a escribir en la universidad: saberes y prácticas de docentes y estudiantes universitarios. Revista Internacional de Investigación en Ciencias Sociales, 2011. Disponível em:

http://revistas.javeriana.edu.co/index.php/MAGIS/article/view/3561/2675

GUZMÁN, R. J.; GUEVARA, M. Concepciones de infancia, alfabetización inicial y aprendizaje de los educadores y educadoras. Revista Latinoamericana de Ciencias Sociales, Niñez y Juventud, 2011. Disponível em: http://revistaumanizales. cinde.org.co/index.php/RevistaLatinoamericana/article/view/76/34

JUSTINO, M. I. S. V.; BARRERA, S. D.Efeitos de uma intervenção na abordagem fônica em alunos com dificuldades de alfabetização. Psicologia: Teoria e Pesquisa, 2012. Disponível em: http://www.scielo.br/pdf/ptp/v28n4/09.pdf

KRAMER, S. A. Leitura e Escrita formação de professores em curso. São Paulo: Editora Ática. 2008.

KRAMER, S.; NUNES M. F. R.; CORSINO, P. Infância e crianças de 6 anos: desafios das transições na educação infantil e no ensino fundamental. Educação e Pesquisa. v.37, n.1, 2011. Disponível em: http://www.scielo.br/pdf/ep/v37n1/v37n1a05. 
LEITE, S. C.; ELLIOT, L. G. Avaliação das capacitações docentes no Programa de Alfabetização de Crianças do Município de Resende, RJ. Meta: Avaliação, 2010. Disponível em:

http://metaavaliacao.cesgranrio.org.br/index.php/metaavaliacao/article/view/95/118

MASSIGNAN, L. R. M.; OLIVEIRA, A. R.; KUBO, O. M.; BOTOMÉ, S. P.Dramatização de histórias infantis e a compreensão de leitura por crianças institucionalizada. Psicologia: Teoria e Pesquisa, 2012. Disponível em: http://www.scielo.br/pdf/ptp/v28n2/04.pdf

MONTEIRO, M. I. Práticas incentivadoras e controle de aprendizagem na alfabetização. Revista do Centro de Educação UFSM, 2010. Disponível em: http://www.redalyc.org/pdf/1171/117116990008.pdf

NOBRE, A.; ROAZZI, A. Realismo Nominal no Processo de Alfabetização de Crianças e Adultos. Psicologia: Reflexão e Crítica, 2011. Disponível em: http://www.scielo.br/pdf/prc/v24n2/14.pdf

OLIVEIRA, J. P.; NATAL, R. M. P.A linguagem escrita na perspectiva de educadores: subsídios para propostas de assessoria Fonoaudiologia escolar. Revista CEFAC, 2012. Disponível em: http://www.scielo.br/pdf/rcefac/v14n6/36-11.pdf

PEREZ, C. L. V. Alfabetização: um conceito em movimento. In: GARCIA, R. L.; ZACCUR, E. (orgs). Alfabetização: reflexões sobre saberes docentes e saberes discentes. São Paulo: Cortez Editora, 2008.

RIBEIRO, N.; SOUZA, L. A. P. Efeitos do(s) letramento(s) na constituição social do sujeito: considerações fonoaudiológicas. Revista CEFAC, 2012. Disponível em: http://www.scielo.br/pdf/rcefac/2011nahead/203-10.pdf

ROCHA, M. S. P. M. L. "Parece um prezinho": famílias de classes populares e o novo Ensino fundamental. Psicologia em Estudo, 2010. Disponível em: http://www.scielo.br/pdf/pe/v15n3/v15n3a06.pdf

SAVELI, E. L. Ecologia de saberes: o diálogo entre a universidade e a alfabetização de adultos. Lectura y Vida, 2010. Disponível em: http://www.lecturayvida.fahce.unlp.edu.ar/numeros/a31n1/31_01_Saveli.pdf

SCHEIBE, L. Valorização e Formação dos Professores para a Educação Básica: Questões desafiadoras para um novo Plano Nacional de Educação. Educação \& Sociedade (Impresso), 2010.

SEVERINO, A. J. Metodologia do trabalho Científico. São Paulo: Cortez, 2002. 
SOARES, M. Letramento: um tema em três gêneros. Belo Horizonte: Autêntica, 1998.

SOARES, M. Letramento e alfabetização: as muitas facetas. Revista Brasileira de Educação. Jan /Fev /Mar /Abr, n 25, p. 5-17, 2004.

SZYMANSKI, M. L. S.; BROTTO, I. J. O. Reflexões sobre as vozes contribuintes para a constituição da subjetividade profissional do docente alfabetizador. Bakhtiniana: Revista de Estudos do Discurso, 2013. Disponível em: http://www.scielo.br/pdf/bak/v8n1/a15v8n1.pdf

VYGOTSKY, L. S.; LURIA, A. R.; LEONTIEV, A. N. Linguagem, desenvolvimento e aprendizagem. São Paulo: Ícone, 1991.

ZIBETTI, M. L. T.; SOUZA, M. P. R. A dimensão criadora no trabalho docente: subsídios para a formação de professores alfabetizadores. Educação e Pesquisa, 2010. Disponível em:

http://www.scielo.br/pdf/ep/v36n2/a03v36n2.pdf.

Recebido em: 20.01 .2017

Aceito em: 24.04.2017 